piece of wing under a compound microscope, when the transparent scales will be seen overhanging the edge like shingles upon a broken roof.

Geo. Dimmock.

(Read before the American Association for the Advancement of Science, at Detroit, Mich., Aug. 14, 1875.)

\title{
On the Insect Fauna of the White Mountains.
}

In a paper published in the July number of Psyche, I drew attention to some of the questions raised by studies on the insects of Mount Washington. In concluding, I suggested the probable identity of Agrotis opipara with A. islandica, and Agrotis scropulana with Pachnobia carnea. I am answered on page 85 of this journal by the remark that " in making synonymical corrections, we want certainties, not probabilities." This does not apply to myself, because I purposely made no synonymical correction in these instances. As to my suggestions, the first has proved itself correct. A specimen of Agrotis islandica sent me by Mr. H. B. Mœschler, from Labrador, cannot possibly be distinguished from my specimen of opipara from Mount Washington. The markings are equally heavy and distinct in both. I justify my remark "obviously unsafe", in the paper referred to, by pointing out that in Dr. Staudinger's original paper on $A$. islandica (Stett. Ent. Zeit., 1857, p. 232), all the differences described on p. 85 of Psyche are considered varietal of islandica. Staudinger says of islandica, "This new Agrotis varies in size, still more in the markings, but most of all in the color." Specimens are described with unicolorously dark primaries, becoming almost smoky brown; this will account for the "gray" specimens differing from the " cinereous" ones. I have Dr. Packard's Iceland specimens of islandica, which formed the basis of Mr. Morrison's knowledge of the species. They belong apparently to an inconspicuously marked form, which seems to vary in color and depth of marking somewhat as velleripennis does. The structure is the same in these specimens of islandica from Iceland and opipara from Mount Washington; the Labrador specimen might have been taken on Mount Washington, and the Mount Washington in Labrador, for all essential points of distinction between them. 
How can Mr. Morrison then say that opipara and islandica "do not bear any resemblance to each other"?

As to A. seropulana, I think I am justified in making a suggestion as to its identity with Pachnobia carnea, from its near resemblance, as to which its author was entirely silent. It differs by the basal markings of the primaries, a character which formed my principal difficulty in suggesting the identity of the species. None of the other characters pointed out by $\mathrm{Mr}$. Morrison in his late paper appear to me to be valid, or other than varietal and inconstant in the limited number of specimens before me. The structure of the feet, so far as I can now see, after a careful re-examination, is the same in both forms. The line on the hind wings, the discal marks and the tone are the same.

In conclusion, I would draw attention to the fact that $\mathrm{Mr}$. Morrison's descriptions of opipara and scropulana, as well as those of other species of the genus in the Proceedings of the Boston Society of Natural History, are too indefinite for identification; so that, did I not possess material received from himself, I would hardly be in a position to refer to his species at all.

A. R. Grote.

\section{BIBLIOGRAPHICAL RECORD.}

Authors and Societies are requested to forward their works to the Editor at the earliest date possible. We ask our readers to inform us of the publication especially of those works which are not generally consulted by entomologists.

B. Pickman Mann.

(Continued from page 96.)

No. 226 is from the Ann. Rep. Mus. Comp. Zool, for 1874.

* 226. C. R. Osten-SAcken. Report on the present condition of the Collection of Diptera of the Museum of Comparative Zoology. p. 14-17.

Grouping of the materials by faunæ; degree of value to be attached to the several groups.

1*227. Sarah Hackett Stevenson. Boys and Girls in Biology; or, Simple Studies of the Lower Forms of Life, based upon the latest Lectures of Prof. T. H. Huxley, and published by his permission. New York, Appleton, 1875. 8vo. pg. 186.

${ }^{1}$ Record furnished by Mr. George Dimmock. 

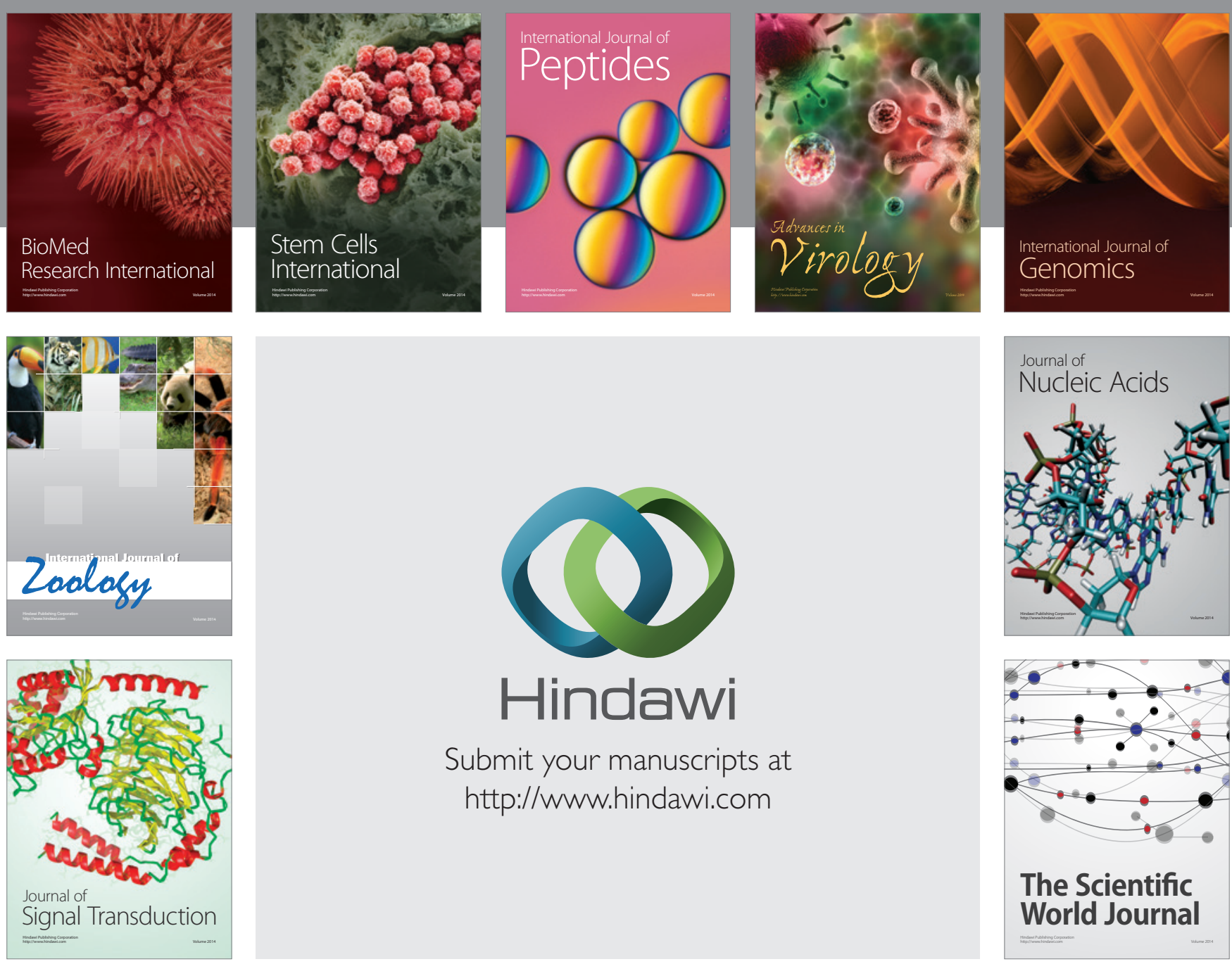

Submit your manuscripts at

http://www.hindawi.com
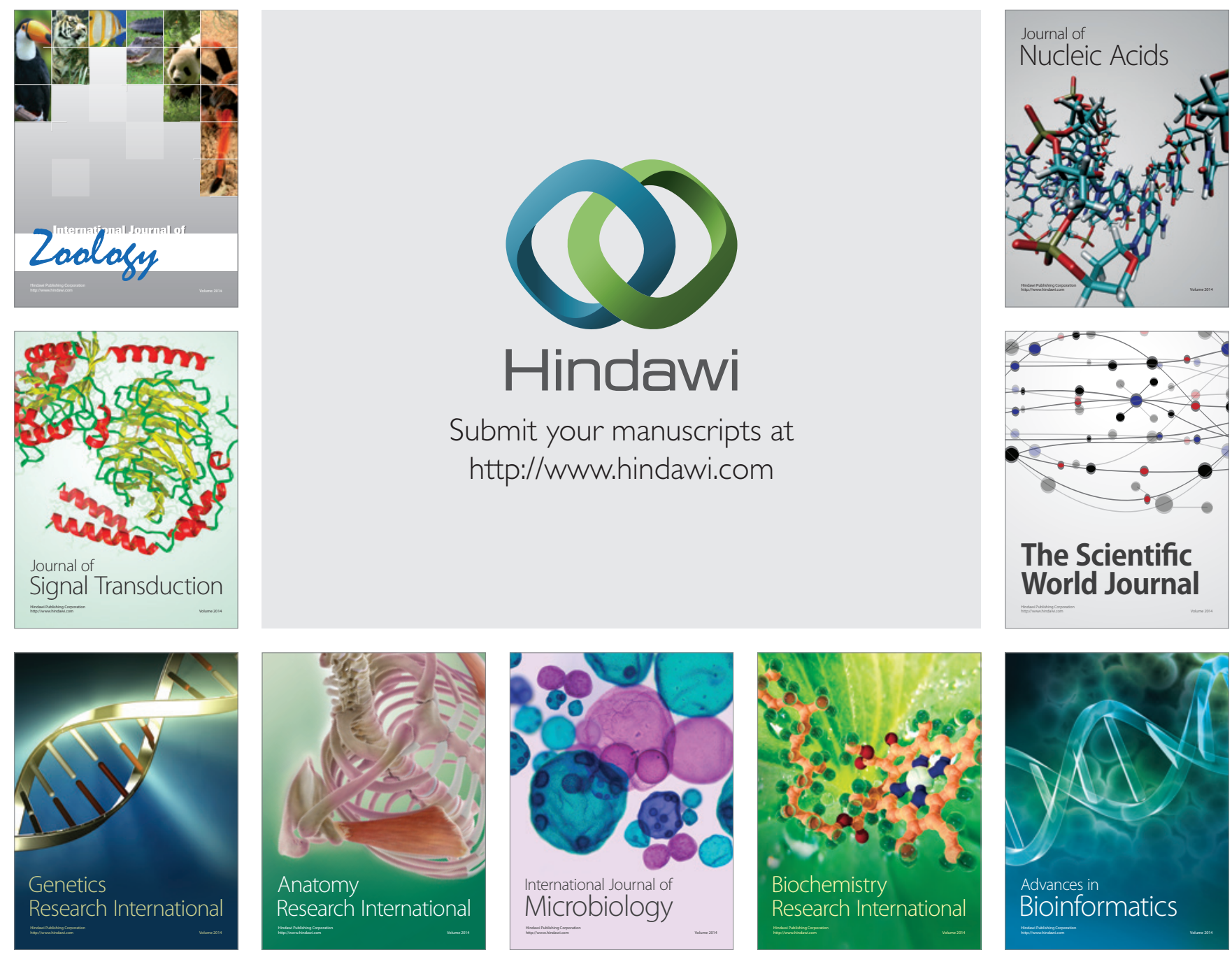

The Scientific World Journal
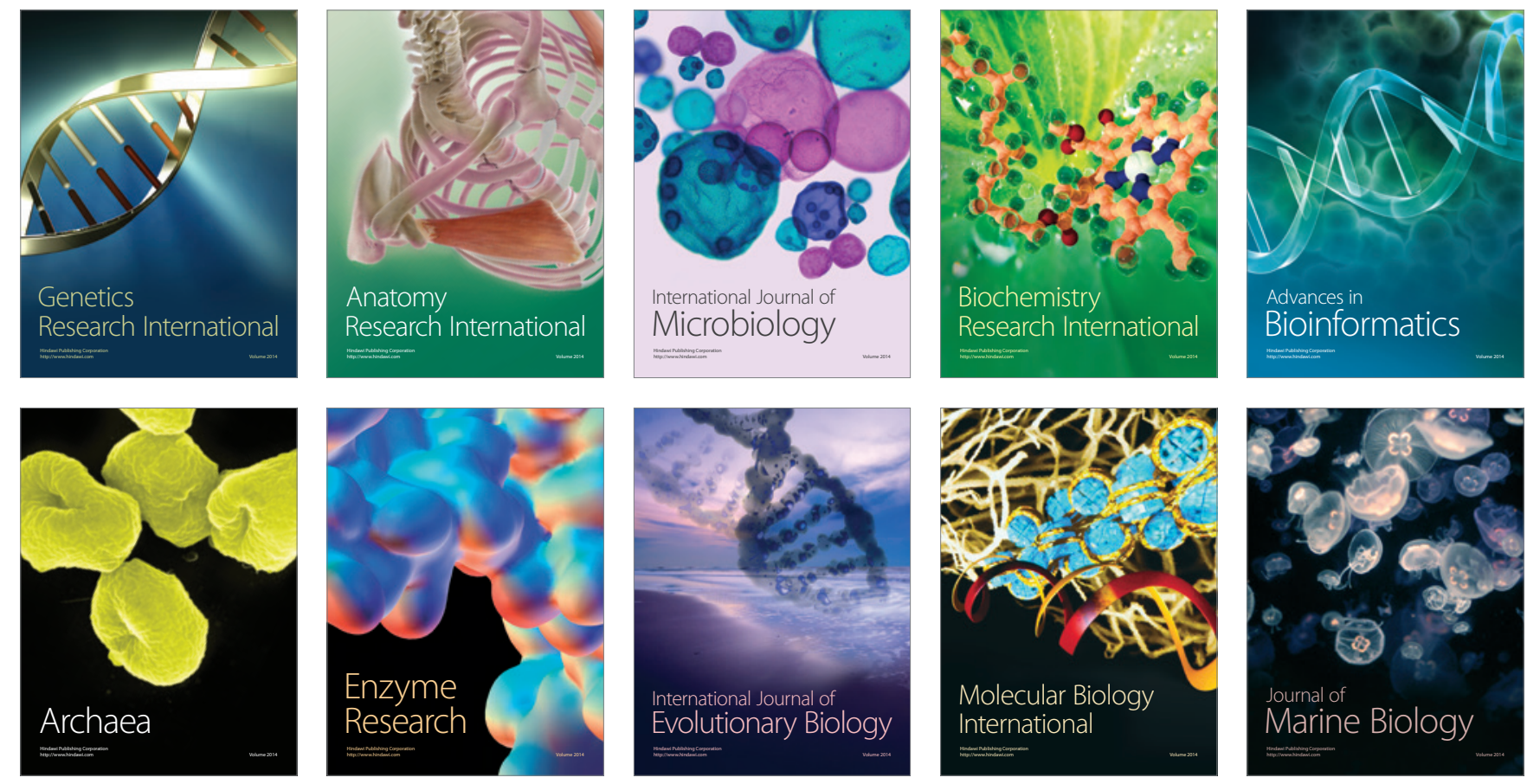